\title{
Working with Lesbian-Headed Families: What Social Workers Need to Know
}

\author{
Misty L. Wall
}

\begin{abstract}
More gay men and lesbian women are choosing parenthood. One common challenge facing lesbian-headed families is how to navigate interactions with societies that are largely homophobic, heterocentric, or unaware of how to embrace nontraditional families. Systems may struggle to adjust services to meet the needs of modern family structures, including families led by lesbian women. The following are three areas of intervention (knowledge, creating affirmative space, and ways to incorporate inclusive language), informed by current literature, that allow social workers to create successful working relationships with members of lesbian-headed families.
\end{abstract}

Keywords: Lesbian, same-sex couples, lesbian-headed families

The landscape for lesbian, gay, bisexual, and transgender individuals (LGBT) has changed vastly within the last decade. For the first time in U.S. history, our president is openly supportive of same-sex marriage and all other formal extensions of equal rights to LGBT individuals. Despite considerable progress, the nuclear heterosexual family is still viewed by parts of western society as the "the norm" and the "preferred" family constellation for child rearing. Despite decades of research that have produced countless empirical studies showing lesbian women to be capable, protective, nurturing, loving parents (see the American Psychological Association for a list of studies), same-sex headed families are viewed by some Americans as deviant and potentially harmful to children (Short, Riggs, Perlesz, Brown, \& Kane, 2007). Many lesbian women desire motherhood and are choosing to become parents in the context of same-sex relationships despite public and private challenges associated with that choice. The purpose of this article is to provide social work practitioners practical, evidence-based interventions so that they may provide effective and affirmative services to lesbian-headed families.

The 2010 U.S. Census report shows 594,000 same-sex couple households in the United States (Lofquist, 2011). Almost half (48\%) of lesbian couples report having a child under 18 in their home (Gates, 2013). While there may be a number of issues with the accuracy of estimates of this hidden population, existing data provide social scientists evidence documenting the prevalence of lesbian women who are parenting.

The definition of family has been evolving for centuries to meet the changing needs of society. Such evolution has included inclusion of adopted children in wills and probated estates, acceptance of mixed-race couples, and grandparents raising grandchildren, among other non-traditionally defined family structures. Narrow definitions of family offer fertile ground for oppression of lesbian-headed families. Nontraditional family structures require practitioners to seek to understand how lesbian women raising children define "family" and the roles within their families. Definitions of

Misty L. Wall, Ph.D., MSSW, LCSW, is an Assistant Professor in the School of Social Work at Boise State University in Boise, ID.

Copyright (C) 2013 Advances in Social Work Vol. 14 No. 2 (Fall 2013), 433-441 
family vary from household to household, but there are a few key themes that social workers must be aware of in order to best support their lesbian clients.

Within lesbian communities, especially lesbian feminist communities, the ideas of lesbian and mother have been mutually exclusive categories. Some lesbian scholars believe that lesbian women do not always recognize the political implications of lesbian motherhood (Corley \& Pollack, 1997), and this sentiment can be alienating for some lesbian mothers (Lewin, 1994). Lesbian women encounter oppression due to their sexual orientation from every aspect of their public and private lives. This oppression is intensified when lesbian women make the decision to have children, because they make this choice in a society that frequently and boisterously protests the lesbian-headed family (Short et al., 2007).

Lewin (1994) followed 135 lesbian women who were raising children for five years and has offered much insight into the plight of mothering while gay. In addition to examining the experience of motherhood, she presents a dichotomous range of lesbian women's perspectives on paternity and paternal involvement. She reported that lesbian women all seemed to consider the role of "father" in their children's lives, but the responses in how to define "father" and to include, or exclude, that person varied widely. For instance, one woman described the void created by lack of male involvement as strictly financial and saw government assistance as sufficient to fulfill that role (Lewin, 1994). Some women felt that raising their children without an active father figure was an advantage. Other women, however, saw filling the "father" role as necessary and felt they were responsible to find diverse male figures, such as grandparents, brothers, or male friends to provide a positive male remodel in their children's lives. Regardless of a lesbian woman's opinion of the place of a traditionally defined father figure, Western culture places value on paternal involvement and considers it to be essential for healthy child development. However, the construct and culture of fatherhood is fluid and dependent upon societal, historical, and economic contexts (Goldberg \& Allen, 2007). The fluid definition of fatherhood provides lesbian women opportunities to redefine traditionally ascribed "father" roles into gender-neutral paradigms that fit within their families.

Lesbian mothers have the opportunity to redefine other family roles as well. Social workers must keep in mind that lesbian-headed households may not be strongly connected to their families of origin, depending on whether or not their biological family is aware of their kin's sexuality or their reaction to the coming out process. Lesbians often rely less on family of origin and more on families of choice (Erwin, 2007). These selected individuals represent a safe community that understands and supports them (Erwin, 2007). Social workers must remember to validate and include, if necessary, families of choice when working with lesbian mothers. When working with couples of color or mixed race couples this is doubly important since extended family and friends are often included in family trees as a cultural standard (Erwin, 2007).

Lesbian mothers have self-reported a variety of strategies and resources to ensure the wellbeing of their families (Short et al., 2007). Women cited that developing rich social networks and intentionally seeking relationships with people from diverse family 
backgrounds were important methods of creating a strong and unique family identity (Short et al., 2007). This research is valuable in that these coping strategies came from lesbian women themselves, rather than counselors or researchers attempting to claim expertise in lesbian women's experiences.

Social service, legal, and political systems in the U.S. are struggling to find ways to meet the needs of increasingly varied models of "family" that are beginning to challenge traditional stereotypes and traditional methods of service provision. As the idea of family expands and shifts to meet the needs of modern families, social workers may be called on to provide direct services to lesbian-headed families. The following are several interventions, informed by current literature, which will allow social workers to create successful working relationships with lesbian-headed families.

\section{Interventions}

\section{Know the Facts}

Common cultural LGBT myths. While American society has succeeded in dispelling many myths about gay men and lesbian women, several harmful and invalid stereotypes persist perpetuating homophobic and heterosexist attitudes, which can negatively impact delivery of effective and competent services. Social workers are not unaffected by homophobia (Black, Oles, \& Moore, 1998; Messinger \& Topal, 1997). Further, the NASW Code of Ethics (1999) calls for social workers to continually strive to improve their knowledge and practice. Some of the harmful myths that exist in our culture include assuming that all LGBT individuals want to be "out" to society, assuming that lesbians dislike or even hate men, assuming that a list of all LGBT people within a community exists or that all gay people know or want to know each other, assuming that identifying as LGBT is not compatible with religion or spirituality, assuming that LGBT individuals are liberal or democratic, assuming that LGBT individuals do not want to be married or have children, and assuming that gender norms are derived entirely from nature rather than society. A particularly harmful stereotype that has prevailed in our society is an association between sexual orientation and child sexual abuse. This list, though long, is by no means exhaustive. The resulting damage from these assumptions and societal myths to individuals and families can be devastating. Thus, in an effort to dispel remaining misinformation, the following is a brief overview of empirically-based information about lesbian and gay-headed families that contradict some of these cultural myths that permeate our society.

Despite research to the contrary, debate continues about how being raised by gay or lesbian parents will affect a child's development and whether or not children of gay or lesbian parents are more likely to be sexually abused (Erwin, 2007). However, research suggests that children raised by gay or lesbian parents may have developmental advantages over children raised by heterosexual parents (Goldberg, Smith, \& PerryJenkins, 2012; Mallon, 2011; Patterson, 2000; Stacey \& Biblarz, 2001). This comparison to heterosexual families is also a form of oppression and heterosexism, as it defines heterosexual families as the norm to which other families are compared (Erwin, 2007; Pollack, 1987). Pollack (1987) discusses the real danger of assuming that lesbian mothers 
are just like other mothers, explaining that doing so "thickens the veil of invisibility" that surrounds lesbian women. Furthermore, available research focusing on lesbian families alone consists of lesbian-headed families of well-educated, white, middle class background, with children from previous marriages. This limiting image further prevents a clear and accurate portrayal of lesbian women, their children and their experiences. This cycle of oppression can affect lesbian women's identities, as sexual orientation is defined and perceived through diverse political, cultural, and ethnic lenses. Internalizing homophobia and heterosexism can affect lesbian women's psychological health and parenting ability (Erwin, 2007). Continuing to view the family through a heterosexual lens will serve to further the oppression experienced by lesbian women and anyone existing outside of a nuclear, heterosexual family context.

Many lesbian-headed families, which can be created through adoption, donor insemination, or mixed families with children from prior relationships, have been found to display higher levels of equality between partners in regards to economic contribution as well as performing work in the home such as childcare and home and property maintenance, and they display advanced parenting skills (Goldberg et al., 2012). Children of lesbian-headed families demonstrate higher levels of attachment when compared to children of heterosexual-headed families (Goldberg et al., 2012; Mallon, 2011; Patterson, 2000; Stacey \& Biblarz, 2001). Despite the cultural myths associating lesbians with a lack of desire and adequacy for partnership or motherhood, the trends of increasing lesbian-headed families and the positive outcomes of their children suggest that these women are desiring and fully capable of creating legitimate and healthy families. One of the most crucial understandings to have when working with LGBT families is to ask about their personal experiences and not make assumptions regarding cultural myths on their individual lives.

Protections and discrimination. Societal oppression exists through the abovementioned myths; however, laws throughout the United States support legal discrimination. Many in our society believe that law protects freedom from oppression, but this is often not the case for individuals who identify as LGBT. While civil rights have expanded to many historically disenfranchised groups, LGBT individuals have often been left behind though things are constantly in flux in different states or cities within states. Various laws regarding bullying, employment protections, fair and equal access to housing, health care for pregnancy planning and partner coverage, marriage equality, availability to petition for second-parent adoption, child custody, donor insemination, and other issues that influence the lives of LGBT individuals, as well as their families, are often not inclusive of LGBT individuals. This lack of legitimized recognition can cause an increase in traumatic experiences and anxiety that would not occur with individuals who do not identify as LGBT, and the large disparity from location to location creates additional inequality of experiences and quality of life (Knauer, 2012). Even the increased political dialogue surrounding elections can increase negative psychological experiences including anxiety, depression, and posttraumatic stress disorder in LGBT individuals (Russel, Bohan, McCarroll, \& Smith, 2011). Currently there is a lack of federal oversight, which leaves civil rights decisions up to state and local governing bodies. Thus it is crucial for practitioners to be educated regarding local and national 
laws as well as the personal experiences of their clients regarding geographical location and legal discrimination.

\section{Create Affirmative Space}

Rapport-building begins when the client enters the agency, or often prior to physical introduction to the agency when the client receives paperwork to complete. Experience has shown that this introductory process is especially important when working with marginalized populations, such as lesbian households because it sets the stage for further development of strong rapport and a trusting therapeutic relationship. Lesbian women who are raising children have unique ways in which they navigate their sexual identity, with varying levels of disclosure depending on the context. Lindsay and colleagues (2011) characterize the degree to which sexual orientation is disclosed on a continuum of proud, selective, and private. They further explain that lesbian women who are considered proud are those women who articulate a commitment to active disclosure of their sexual orientation as a means of advocacy or protection for their children. Selective disclosure refers to women who are just that, selective, regarding to whom and when they disclose their sexual orientation. Women who attempt to disguise their relationships, especially relationships to the non-legal or non-biological parent, choose to do so because they feel out of place, unwelcomed, or excluded when working within heteronormative systems. Finally, private denotes deliberate and active non-disclosure. Levels of authenticity and disclosure are directly related to the perceived level of acceptance and support within the social context and lower levels of disclosure are related to the desire to keep their children safe in systems that are homophobic (Lindsay et al., 2011).

Lesbian clients may find it difficult to ask for or accept help, if the physical environment is not affirmative (Hunter \& Hickerson, 2003). Creating affirmative space extends beyond an individual social worker's office to include the entire agency area. One way to create affirmative space agency-wide is to include pictures, periodicals, or other media that include various family constellations, equality organizations such as Parents and Friends of Lesbians and Gays (PFLAG) or the Human Rights Campaign (HRC), and written statements about the agency's commitment to providing equal services (Mallon, 2000). Providing images of same-sex couples, lesbian-headed families, or the like sends the message that all families are valued and encouraged to attend and be fully open about their sexual orientation and family constellations. Within each social worker's office he/she could include resources that are specifically lesbian and gay friendly (Eldridge \& Barnett, 1991). Mercier and Harold (2003) interviewed 21 lesbianheaded families about their interfaces with schools and found that many reported feeling that their school systems were attempting to be inclusive of their families, but were doing so with a limited array of resources. Further, lesbian-headed families are often knowledgeable about resources regarding their families and eager to share books, resources, pictures, or similar resources to create systems that affirm their families (Mercier \& Harold, 2003).

Members of lesbian-headed families consistently mention heteronormative systems' inability to "see" them as they are (Eldridge \& Barnett, 1991; Mercier \& Harold, 2003). Lesbian parents frequently report that even when they are intentionally out with child 
care providers, school personnel, or other helping professionals, the helping professional reorganizes their family structure into a more common, heteronormative structure, mistaking partners for sisters, grandparents, or the like (Mercier \& Harold, 2003; Skattebol \& Ferfolja, 2007), perpetuating invisibility and oppression. When lesbian women have parts of their family system minimized, or restructured to fit within the norm, the message of otherness, less than, is internalized, further marginalizing lesbian parents and their children. One solution is to be aware of personal assumptions about families, let the client lead introductions of themselves and their families, and ask clarifying questions when necessary.

Lack of these LGBT-affirming environments, images, and literature can lead clients to feel marginalized, unwelcome, and can increase likelihood of internalized homophobia from living in a heterocentric society (Lindsay et al., 2011; Szymanski \& Chung, 2008). Having a safe, confidential space is crucial in contributing to a strong therapeutic relationship and experience for lesbian women (Pixton, 2003).

\section{Use Inclusive Language}

The first encounters with a practitioner or agency are generally intake or registration forms or informational surveys. Often forms present heterosexist language including "married, single or divorced" or describe relationships to the client with words such as "spouse," "mother," and "father." Redesigning forms to include language that is inclusive of all family structures will send a signal to lesbian clients that their families are understood and valued by the practitioner as well as by the entire agency. In general, it is important to always provide an option for "other" and a blank space for the client to

provide appropriate information. Utilize the client's language and always ask for definitions or clarification rather that making assumptions. For a comprehensive list of replacement options for current agency forms, please see Table 1.

Table 1. Commonly Utilized Language Contrasted with More Inclusive Language Options

Language Currently Utilized

Marital Status:

Divorced, Married, Separated, Single

Name of Spouse

Mother/Father

Sex: Male, Female

Gender: Man, Woman

Not Applicable
More Inclusive Options

Relationship Status:

Civil Union, Divorced, Domestic Partnership, Legally Separated, Married, Partnered, Single, Separated, Unknown, Widowed, Other

Name of Partner

Parent, Co-Mother, Co-Father

Sex: Male, Female, Intersex, Other

Gender Identity: Male, Female, Transgender male to female (MTF), Transgender female to male (FTM), Gender Queer, Other

Child's Status: biological, adopted, foster 
In situations where adoption is not a preferred or viable option for lesbian women, an important issue to focus on is the role of the "co-mother," or the non-biological parent in a lesbian family. Motherhood is associated with biology and childbirth in society, making the role of co-mother a difficult and often isolating position. In her published diary, Gray (1987) writes of the disconnection she experienced during the first month after the birth of her partner's child. She explains she felt "very left out because I can't feed him” as well as "hurt by Kathleen's seeming unwillingness to share that fundamental task" (Gray, 1987). She later comments, "no one's allowed to have two mommies," as was evident when people approached her family and asked, "Who's the mom?” or "whose baby is it?" (Gray, 1987).

How lesbian co-mothers are perceived and treated in society is another indicator of heterosexism along with the denial of basic cultural celebrations and landmarks to lesbian and gay families that include marriage, anniversaries, baby showers, and so forth. Social workers have the opportunity to encourage lesbian families to create their own rituals to celebrate their union, and be inclusive of two mothers, two fathers, and other nonnormative family structures as agencies celebrate. Family rituals and being included in agencies' events validate and empower lesbian couples, as well as create a sense of legitimacy and family identity (Erwin, 2007). Utilizing the correct language and exploring the individual narrative of clients' families is crucial to establishing a trusting relationship that validates all family structures and is required for a working therapeutic alliance.

\section{Conclusion}

The attitudes of Americans toward lesbian women have changed dramatically within the last ten years. The majority of Americans support same-sex marriage and even more support equal protections regardless of sexual orientation. While the political landscape continues to grow more tolerant of sexual minorities, lesbian women still face real risks when disclosing their sexual orientation. Further, many lesbian women are hesitant to disclose their sexual orientation. The growing forms of non-traditional family structures pose considerable challenges to heteronormative systems.

Because of their direct contact with clients and their ethical commitment to oppose oppressive systems, social workers are likely to be the agency representatives who are in the best position to advocate for corrections within heteronormative systems that marginalize lesbian-headed families. Suggestions for social workers presented in this paper include: 1) knowing the facts about the challenges faced by lesbian-headed families, with special attention paid to legal and social risks associated with "coming out" as a lesbian or a lesbian mother; 2) empowering social workers to create affirmative space within their agencies for lesbian-headed families by, for example, supporting changes to policy, paperwork, and physical surroundings that suggest lesbian-headed families are seen and valued; and 3) reworking language to be inclusive of lesbianheaded families. In summary, working with lesbian-headed families may be challenging for social workers who often report feeling unaware of the needs of this population. However, addressing these three key areas (knowledge, space, and language) can 
transform an agency into an affirmative and efficient resource for lesbian-headed families.

\section{References}

Black, B., Oles, T., \& Moore, L. (1998). The relationship between attitudes: Homophobia and sexism among social work students. Affilia: Journal of Women and Social Work, 13(2), 166-189.

Corley, T. J., \& Pollack, R. H. (1997). Do changes in the stereotypic depiction of a lesbian couple affect heterosexuals' attitudes toward lesbianism? Journal of Homosexuality, 32(2), 1-17.

Eldridge, N. S., \& Barnett, D. C. (1991). Counseling gay and lesbian students. In N. J. Evans \& V. A. Wall (Eds.), Beyond tolerance: Gays, lesbians, and bisexuals on campus (pp. 147-178). Alexandria VA: American College Personnel Association.

Erwin, T. M. (2007). Two moms and a baby: Counseling lesbian couples choosing motherhood. Women \& Therapy, 30(1/2), 99-149.

Gates, G. J. (2013). LGBT Parenting in the United States. Retrieved from http://williamsinstitute.law.ucla.edu/research/census-lgbt-demographics-studies/lgbtparenting-in-the-united-states/

Goldberg, A. E., \& Allen, K. R. (2007). Imagining men: Lesbian mothers’ perceptions of male involvement during the transition to parenthood. Journal of Marriage and Family, 69(2), 352-365.

Goldberg, A. E., Smith, J. Z., \& Perry-Jenkins, M. (2012). The division of labor in lesbian, gay, and heterosexual new adoptive parents. Journal of Marriage and Family, 74(4), 812-828.

Gray, P. (1987). The other mother: Lesbian co-mother's journal. In S. Pollack \& J. Vaughn (Eds.), Politics of the heart: A lesbian parenting anthology (pp. 133-139). Ithaca, NY: Firebrand Books.

Hunter, S., \& Hickerson, J. (2003). Affirmative practice. Washington, DC: NASW Press.

Knauer, N. J. (2012). Legal consciousness and LGBT research: The role of the law in the everyday lives of LGBT individuals. Journal of Homosexuality, 59(5), 748-756.

Lewin, E. (1994). Negotiating lesbian motherhood: The dialects of resistance and accommodation. In E. N. Glenn, G. Chang, \& L. R. Forcey (Eds.), Mothering: Ideology, experience, and agency (pp. 333-354). London, UK: Routledge.

Lindsay, J., Perlesz, A., Brown, R., McNair, R., de Vaus, D., \& Pitts, M. (2006). Stigma or respect: Lesbian-parented families negotiating school settings. Sociology, 40(6), 1059-1077.

Lofquist, D. (2011). Same-Sex Couple Households: American Community Survey Briefs. Washington, DC: United States Census Bureau. Retrieved from http://www.census.gov/prod/2011pubs/acsbr10-03.pdf 
Mallon, G. P. (2000). A call for organizational trans-formation. Journal of Gay \& Lesbian Social Services, 10(3-4), 131-142.

Mallon, G. P. (2011). The home study assessment process for gay, lesbian, bisexual, and transgender prospective foster and adoptive families. Journal of GLBT Family Studies, 7(1-2), 9-29.

Mercier, L. R., \& Harold, R. D. (2003). At the interface: Lesbian parent families and their chlidren's schools. Children \& Schools, 25(1), 35-47.

Messinger, L., \& Topal, M. (1997). Are you married? Two sexual-minority students' perspectives on field placement. Affilia, 12, 106-113.

National Association of Social Workers. (1999). Code of ethics of the National Association of Social Workers. Washington, DC: NASW Press.

Patterson, C. J. (2000). Family relationships of lesbians and gay men. Journal of Marriage and Family, 62, 1052-1069.

Pixton, S. (2003). Experiencing gay affirmative therapy: An exploration of clients' views of what is helpful. Counseling and Psychotherapy Research: Linking research with practice, 3(3), 211-215.

Pollack, S. (1987). Lesbian mothers: A lesbian-feminist perspective on research. In S. Pollack \& J. Vaughn (Eds.), Politics of the heart: A lesbian parenting anthology (pp. 316-324). Ithaca, NY: Firebrand Books.

Russell, G., Bohan, J., McCarroll, M., \& Smith, N. (2011). Trauma, recovery, and community: Perspectives on the long-term impact of anti-LGBT politics. Traumatology, 17(2), 14-23.

Short, E., Riggs, D. W., Perlesz, A., Brown, R., \& Kane, G. (2007). Lesbian, gay, bisexual and transgender (LGBT) parented families: A literature review prepared for the Australian Psychological Society. Melbourne, VIC: Australian Psychological Society. Retrieved from http://www.psychology.org.au/publications/statements/lgbt_families/

Skattebol, J., \& Ferfolja, T. (2007). Voices from an enclave: Lesbian mothers' experiences of child care. Australian Journal of Early Childhood, 32(1), 10-18.

Stacey, J., \& Biblarz, T. J. (2001). (How) does the sexual orientation of parents matter? American Sociological Review, 66(2), 159-183.

Szymanski, D. M., \& Chung, Y. B. (2008). Internalized homophobia in lesbians. Journal of Lesbian Studies, 7(1), 115-125.

\section{Author note:}

Address correspondence to: Misty L. Wall, Ph.D., MSSW, LCSW, Assistant Professor, Boise State University School of Social Work, 1910 University Drive, Boise, ID 837251940. Email: mistywall@boisestate.edu 